\title{
Pseudomyogenic Hemangioendothelioma (Epithelioid Sarcoma- like Haemangioendothelioma) - Case Report of a Rare Entity
}

\author{
B.N. Kumarguru. ${ }^{1 *}$, N.Navya. ${ }^{1}$, R.Prashanth. ${ }^{1}$, C.A.Arathi. ${ }^{1}$, Bharath B. ${ }^{2}$ \\ 'Department of Pathology, PES Institute of Medical Sciences and Research [PESIMSR], India \\ ${ }^{2}$ Department of Surgery, PES Institute of Medical Sciences and Research [PESIMSR], India
}

\begin{abstract}
Pseudomyogenic Hemangioendothelioma (Epithelioid Sarcoma-like Haemangioendothelioma) is a rare soft tissue tumor of endothelial origin. It is a distinctive neoplasm having indolent behaviour. A 27-year-old male presented with history of multiple small ulcers over right shoulder region since 2 months. On examination, diffuse indurated plaques were seen over the right shoulder with multiple ulcers. A Provisional diagnosis of non-healing ulcer over right shoulder was offered. Pus culture was positive for coagulase negative Staphyloccus species. The lesion was excised and sent for histopathology. Microscopy showed ulcerated epidermis. Subepithelium showed tumor tissue composed of cells arranged in fascicles, sheets and irregular nodules. Individual tumor cells were oval to spindle shaped cells having brightly eosinophilic cytoplasm and vesicular nucleus with noticeable nucleoli. At places, endothelial cell proliferation and neovascularization was seen. Possibility of epithelioid sarcoma, epithelioid hemangioendothelioma and malignant melanoma was considered. Immunohistochemistry was performed. Neoplastic cells were positive for vimentin, CD31, CK19 and negative for CD34, HMB45 and EMA. A final diagnosis of Epithelioid sarcoma-like Hemangioendothelioma (Pseudomyogenic Hemangioendothelioma) was offered. It is an unusual pathological entity with an unique clinical presentation. Histopathology is challenging. Immunohistochemistry is not only confirmatory, but also mandatory to solve the diagnostic dilemma.
\end{abstract}

Keywords: Neoplasm, Ulcer, Shoulder, Immunohistochemistry

\section{Introduction}

Pseudomyogenic Hemangioendothelioma (Epithelioid Sarcoma-like Haemangioendothelioma) is a rare soft tissue tumor of vascular origin..$^{[1]}$ It is a distinctive, locally aggressive, rarely metastasizing tumor having indolent behaviour. ${ }^{[1,2,3]}$ The neoplasm occurs more frequently in young adult males. ${ }^{[2,4]}$ It usually affects the lower limbs. But the upper limbs, trunk and face are less commonly involved. ${ }^{[4]}$ It is quite distinct from epithelioid hemangioendothelioma. ${ }^{[5]}$ Both, clinically and histopathologically, it mimicks epithelioid sarcoma and needs immunohistochemistry for definitive diagnosis. ${ }^{[3,6]}$ We hereby report a case of Pseudomyogenic Hemangioendothelioma (Epithelioid Sarcoma-like Haemangioendothelioma) in a 27 -year-old male presenting with an ulcerated lesion over right shoulder.

\section{Case Report}

A 27-year-old male presented with history of multiple small ulcers over right shoulder region since 2 months. The lesion started as small nodules, that later transformed into ulcerative lesion. On examination, diffuse indurated plaques were seen over right shoulder with multiple ulcers, largest measuring about $2 \times 2 \mathrm{~cm}$. The ulcer showed beaded edges and the floor of the ulcer was covered with yellowish slough. Right supraclavicular lymph nodes were enlarged.
A Provisional diagnosis of non-healing ulcer over right shoulder was offered. Differential diagnoses of viral infection, cutaneous tuberculosis, actinomycosis and pyoderma gangrenosum were considered. Pus culture was positive for coagulase negative Staphyloccus species. ESR was elevated $(21 \mathrm{~mm} /$ first hour). Other investigations showed no significant abnormality. The lesion was excised and sent for histopathology.

Grossly, we received a skin covered soft tissue mass measuring $6 \times 2.5 \times 1 \mathrm{~cm}$. External surface showed ulceration. Cut section showed grey-white area beneath the ulcerated area. (Fig.1) Microscopy showed ulcerated epidermis. (Fig.2a) Subepithelium showed tumor tissue composed of cells arranged in fascicles, sheets and irregular nodules. (Fig. 2b) Individual tumor cells were medium sized to large, oval to spindle shaped cells having moderate amount of brightly eosinophilic cytoplasm and vesicular nucleus with noticeable nucleoli. Some of the tumor cells showed mild pleomorphism and intracytoplasmic vacuolation. (Fig. 2c) At places endothelial cell proliferation and neovascularization was seen. Amidst the tumor tissue, few polymorphs and congested blood vessels were seen. The tumor cells were seen to infiltrate into the adnexal structures and subcutaneous adipose tissue. (Fig.2d) At places, perineural infiltration was seen. But all resected surgical margins were free from tumor. 
Based on histopathological features, possibility of epithelioid sarcoma, epithelioid hemangioendothelioma and malignant melanoma was considered. Immonohistochemistry was performed. Neoplastic cells were positive for vimentin, CD31, CK 19 and negative for CD 34, HMB 45 and EMA. (Fig.3a-d) A final diagnosis of Epithelioid sarcoma-like Hemangioendothelioma (Pseudomyogenic Hemangioendothelioma) was offered. Post-operative period was uneventful and the patient was discharged in stable condition.

\section{Discussion}

Pseudomyogenic Hemagioendothelioma $(\mathrm{PMH})$ is a distinct entity, which was first described as "fibroma-like variant of epithelioid sarcoma" by Mirra et al al in 1992. Since then, the neoplasm has undergone changes in nomenclature

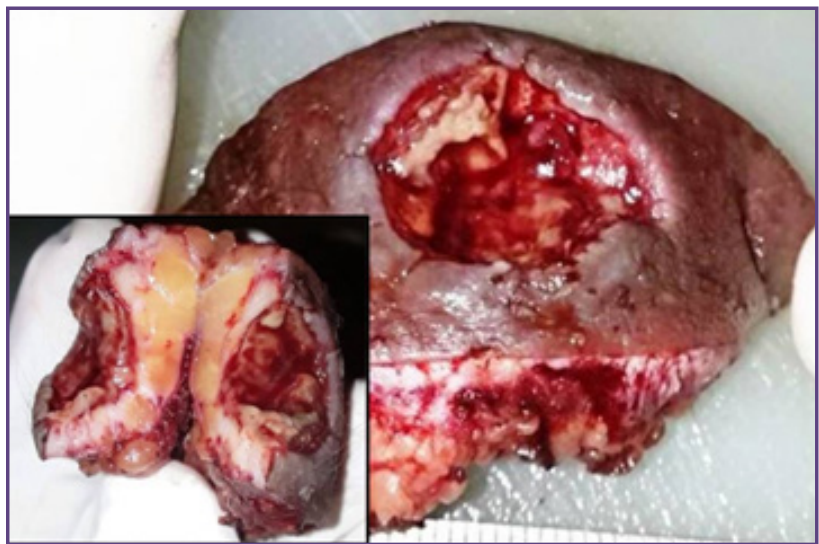

Fig. 1: Gross photograph of skin covered lesional tissue mass displaying ulceration. Inset: Cut section show greywhite area beneath the ulcerated area.

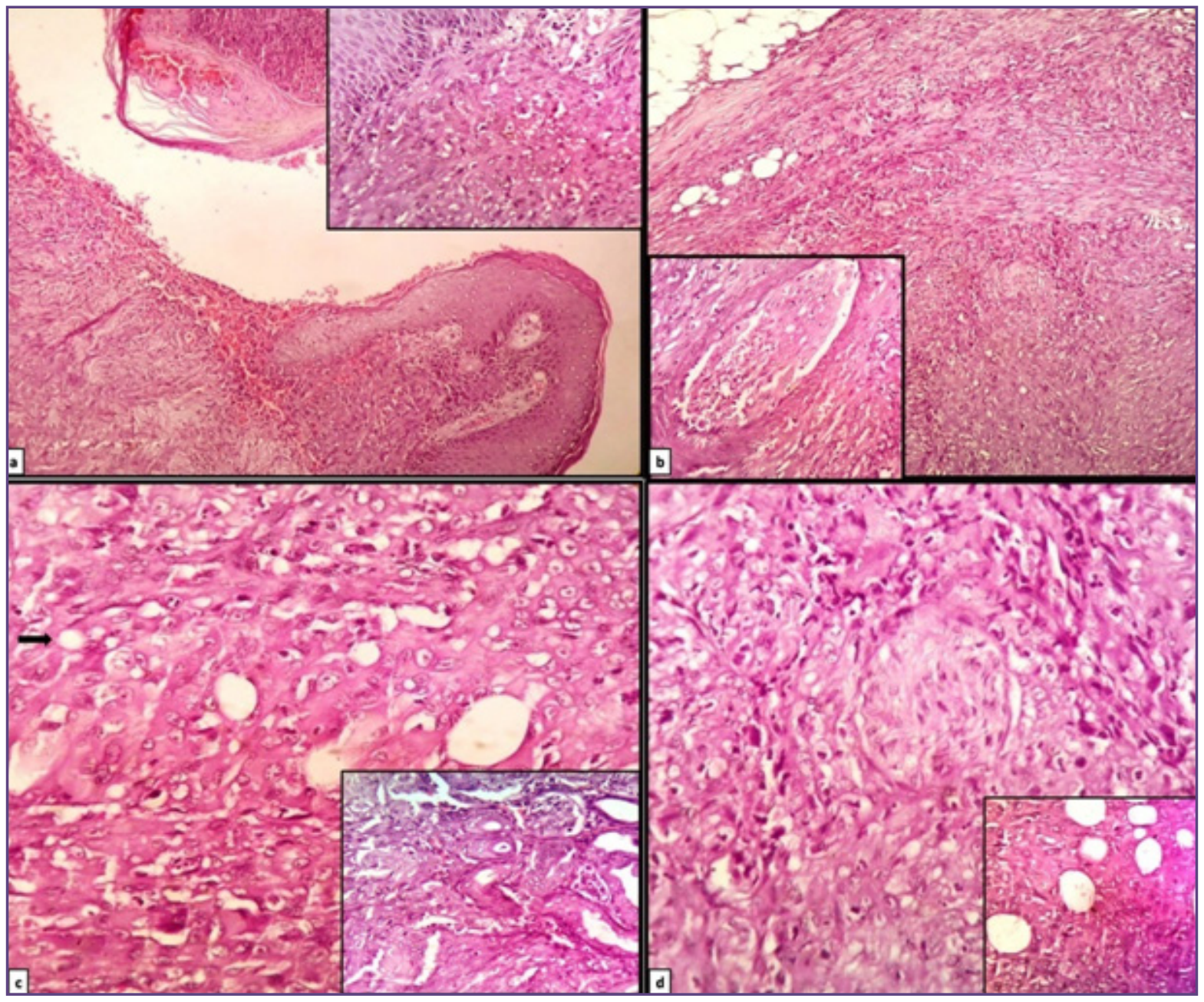

Fig.2a-d: (a) Ulcerated epidermis. (H\&E, X40). Inset: Subjacent tumor tissue. (H\&E, X400) (b) Tumor cells in fascicles and irregular nodules. (H\&E, X100). Inset: Neovascularization. (H\&E, X400) (c) Tumor cells having pleomorphic vesicular nucleus, noticeable nucleoli and cytoplasmic vacuolation (arrow). Inset: Periadenxal infiltration. (H\&E, X400) (d) Perineural infiltration. Inset: Adipose tissue infiltration. (H\&E, X400). 


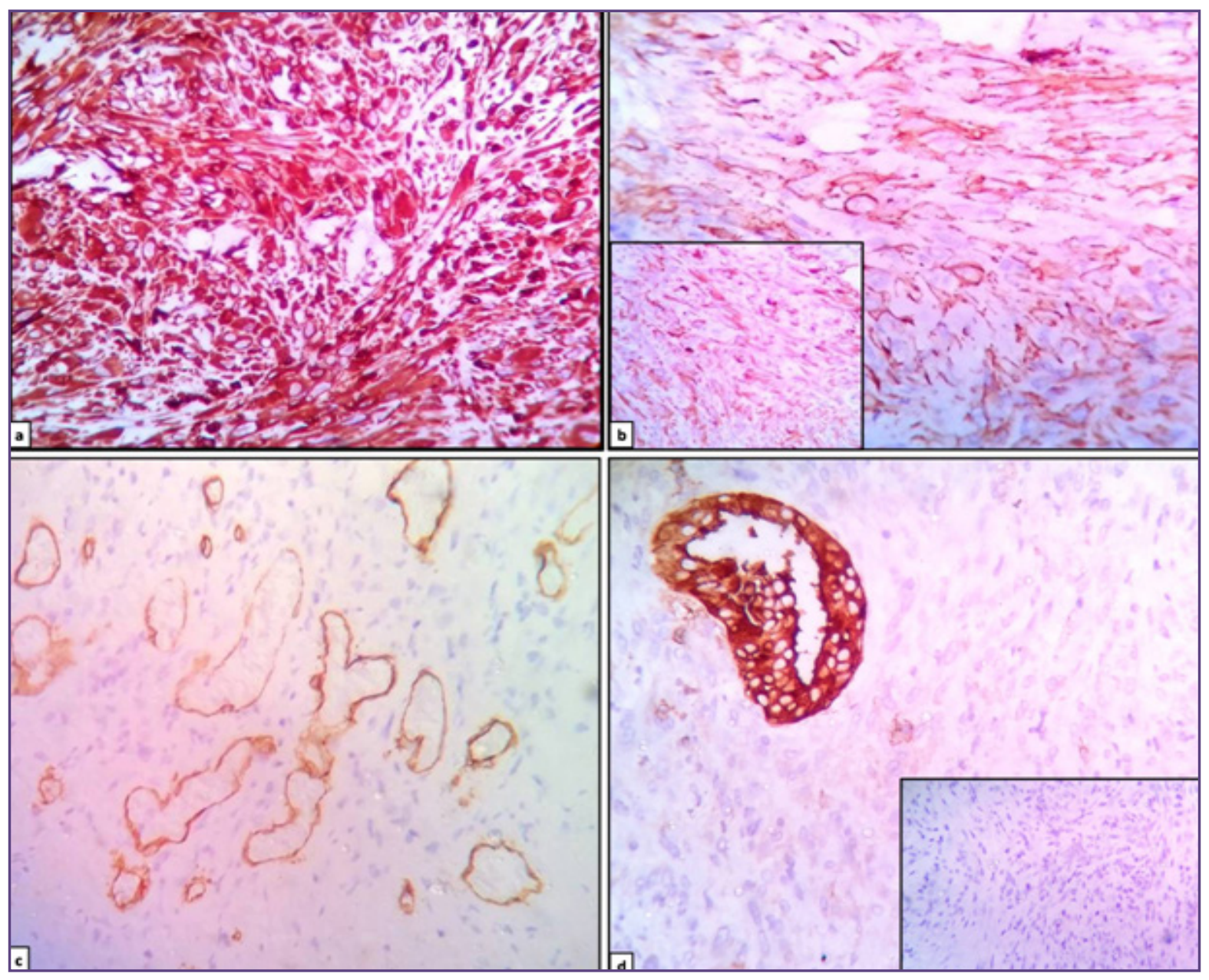

Fig.3a-d: (a) Neoplastic cells strongly positivity for vimentin. (IHC, X400). (b) Neoplastic cells positive for CD31. Inset: Neoplastic cells positive for CK19. (IHC, X400). (c) Neoplastic cells negative for CD34. (IHC, X400). (d) Neoplastic cells negative for EMA. Inset:Neoplastic cells negative for HMB45. (IHC, X400).

as its biological behaviour was established. ${ }^{[1]}$ In 2003, Billings SD et al proposed to rename it as "epithelioid sarcoma-like hemangioendothelioma (ES-H)" based on immunophenotypic characteristics. ${ }^{[1,6]}$ Hornick and Fletcher named the tumor as "pseudomyogenic (fibromalike) variant of epithelioid sarcoma". ${ }^{[1,5]}$ But later it was renamed as "Pseudomyogenic Hemagioendothelioma" as it was recognized to have vascular origin. ${ }^{[1]}$ Previous literature categorizes the entity as low grade vascular neoplasm. ${ }^{[1,3]}$ Currently, it is categorized as "Pseudomyogenic Hemagioendothelioma" under intermediate grade vascular tumor of soft tissue in 2013 WHO fascicle. ${ }^{[4]}$

The neoplasm is more frequently seen in young adults and predominantly in males. ${ }^{[5]}$ Karakasli A et al ${ }^{[3]}$ and McGinity et $\mathrm{a}^{[5]}$ described a case of a PMH in male patients in their case reports. In contrast, Rawal $\mathrm{YB}$ et $\mathrm{al}^{[1]}$ and Fan $\mathrm{C}$ et $\mathrm{a}^{[2]}$ documented the lesion in female patients in their case reports. Rawal YB et $\mathrm{al}^{[1]}$ and McGinity et $\mathrm{al}^{[5]}$ reported $\mathrm{PMH}$ in third decade in their case report. In contrast, Fan $\mathrm{C}$ et $\mathrm{al}^{[2]}$ documented the lesion in fifth decade and Karakasli et $\mathrm{al}^{[3]}$ documented the lesion in sixth decade in their case reports. In the present case, the lesion was seen in a male patient in his third decade of life.

The neoplasm typically affects the lower limb, arm, trunk, and head \& neck region in the decreasing order of frequency. ${ }^{[1]}$ Fan $\mathrm{C}$ et al ${ }^{[2]}$ described a case of $\mathrm{PMH}$ in the left lower limb. Karakasli A et al ${ }^{[3]}$ reported occurrence of $\mathrm{PMH}$ in right index finger and was associated with bone invasion. McGinity et $\mathrm{al}^{[5]}$ documented a rare case in which the lesion was seen in the thoracic spine. Rawal YB et $\mathrm{al}^{[1]}$ described an unusual case of PMH in the oral cavity. In the present study, the site of involvement was right shoulder. 
Clinically, the neoplasm most commonly presents as multiple nodules. ${ }^{[6]}$ Fan $\mathrm{C}$ et $\mathrm{al}^{[2]}$ described a case of PMH presenting as multiple nodules in their case report. In the present case, the patient presented with ulcerated lesion over right shoulder. The lesion may involve multiple planes such as dermis, subcutaneous tissue, skeletal muscle and bone. The tumor may present as superficial or deep soft tissue masses. ${ }^{[1]}$

Resquena $\mathrm{L}$ et $\mathrm{al}^{[6]}$ appreciated histomorphological features similar to that which is documented in the present case report. McGinity et $\mathrm{al}^{[5]}$ also observed intracytoplasmic vacuolation. Rawal YB et $\mathrm{al}^{[1]}$ observed similar morphological features except for intracytoplasmic vacuolation and vascular changes.

Epithelioid hemangioendothelioma is a malignant angiocentric vascular neoplasm composed of epithelioid tumor cells arranged in cords in a myxohyaline stroma. ${ }^{[4]}$ The tumor cells show intracytoplasmic vacuolation. ${ }^{[4,7]}$ The most epithelioid hemangioendothelioma have an indolent course. ${ }^{[4]}$ Epitheiloid sarcoma is an high grade aggressive neoplasm with nodular growth pattern composed of epithelioid cells and spindle cells. ${ }^{[4.8]} \mathrm{PMH}$ is an intermediate grade vascular neoplasm morphologically exhibiting features of both epithelioid hemangioendothelioma and epitheiloid sarcoma.

$\begin{array}{llr}\text { Differential diagnosis } & \begin{array}{c}\text { includes } \\ \text { epithelioid }\end{array} & \begin{array}{r}\text { epithelioid } \\ \text { semangioendothelioma, }\end{array}\end{array}$ angiosarcoma, malignant melanoma, rabdomyosarcoma, leiomyosarcoma, malignant peripheral nerve sheath tumor. Immunohistochemistry plays an important role to establish the diagnosis and exclude the other neoplasms. ${ }^{[1,2,6]}$ In the present case, the neoplastic cells were positive for vimentin, CD31, CK19 and negative for CD34, HMB-45 and EMA. Rawal YB et al ${ }^{[1]}$, Karakasli A et $\mathrm{al}^{[3]}$ observed similar immunophenotypic characteristics of neoplastic cells in their case report.

A casual relationship between chronic bartonella infection and development of epithelioid hemangioendothelioma has been suggested as a hypothesis. Bartonella has an unique ability to invade and induce long-lasting intraerythrocytic and intraendothelial infection. They also induce vascular endothelial growth factor mediated vascular proliferation. ${ }^{[7]}$ Even in the present case, pus culture was positive for coagulase negative Staphyloccus species. It may be hypothesized that bacterial agents may play an important role in pathogenesis of PMH. But this needs to be proven by future studies.

Trombetta et al demonstrated balanced translocation between chromosomes 7 and 19 [t(7;19) (q22q22)] as the sole change by using G-banding analysis. Unbalanced translocation der $(7) \mathrm{t}(7 ; 19)$ was also identified in one case by using interphase FISH analysis. ${ }^{[4,5]}$

Treatment of choice is complete excision followed by adjuvant therapy and close follow-up due to the risk of recurrence. ${ }^{[5]}$

\section{Conclusion}

As the eyes cannot see what mind does not know, pathologists should be aware of newer and unusual diagnostic entities. Pseudomyogenic Hemagioendothelioma (Epithelioid Sarcoma-like Haemangioendothelioma) is an unusual pathological entity with an unique clinical presentation. Clinically, it poses a diagnostic dilemma. Histopathology is challenging, but helpful in establishing the diagnosis. It is such a lesion in which immunohistochemistry is not only confirmatory, but also mandatory to solve the diagnostic dilemma and arrive at the correct diagnosis.

\section{Acknowledgement}

We sincerely thank Dr.Swethadri.G.K, Professor, department of Pathology, PESIMSR and Mr.Prakash.M, Laboratory technician for the kind co-operation extended to us for the work up of the case.

\section{References}

1. Rawal YB, Anderson KM, Dodson TB. Pseudomyogenic Hemangioendothelioma: A vascular Tumor Previously Undescribed in the Oral Cavity. Head and neck Pathol 2017;11:525-30.

2. Fan C, Yang L, Lin X, Wang E. Pseudomyogenic hemangioendothelioma/epithelioid saroma-like hemangioendothelioma of the lower limb: report of a rare case. Diagnostic Pathology 2015;10:150. DOI10.1186/ s13000-015-0384-z.

3. Karakasli A, Karaaslan A, Eduran M, Capkin S, Tuna EB, Havitcioglu H. Pseudomyogenic (Epithelioid sarcomalike) hemangioendothelioma with bone invasion. Journal of Orthopaedics 2014;11:197-9.

4. Fletcher CDM, Bridge HA, Hogendoorn PCW, Mertens F editors. World health organization classification of tumors of soft tissue and bone, Lyon, France: IARC Press;2013. pp9-238.

5. McGinity M, Bartanusz V, Dengler B, Birnbaum L, Henry J. Pseudomyogenic hemangioendothelioma (epithelioid sarcoma-like hemangioendothelioma, fibroma-like variant of epithelioid sarcoma) of spine. Euro Spine J 2013;22:S506-S511

6. Resquena L, Santonja C, Martinez-Amo JL, Saus C, Kutzner H. Cutaneous Epithelioid Sarcomalike (Pseudomyogenic) Hemangioendothelioma: A Little-Known Low-Grade Cutaneous Vascular Neoplasm. JAMA Dermatol 2013;149:459-65. 
7. Sardarao A, Bardoscia L, Petruzzelli MF, Portaluri M. Epithelioid hemangioendothelioma: An overview and update on a rare vascular tumor. Onclogy Reviews 2014;8:82-90.
8. Sobanko JF, Meijer L, Nigra TP. Epithelioid Sarcoma: A Review and Update. The Journal of Clinical and Aesthetic Dermatology 2009;2:49-54.

*Corresponding author:

Dr. Kumarguru B.N, 'Sri’nivasa, No: 204, 9th cross, BEML Layout, I stage, Basaveshwaranagara, Bangalore- 560079. Karnataka, India Phone: +919845813257

Email: kumarguru1978@yahoo.com

Financial or other Competing Interests: None. 